The report contains much valuable information about the cost of employing men on research and development. In 1963 the average cost worked out at $\$ 37,600$ for every skilled person so employed-an increase of 15 per cent since 1957. Within this average value, however, there were important differences. The higher unit costs of research and development were to be found in the development of motor vehicles and other forms of transport, where one man year accounted for $\$ 49,500$ in 1963. Research and development in the aircraft and missile industry was marginally cheaper at $\$ 47,400$ a man year. In the petroleum industry, the cost ratio worked out at $\$ 36,000$, while research and development in forestry and furniture cost a mere $\$ 20,400$. Just as larger companies employed proportionately more skilled people, so it seems they provide them with more funds; the cost of research and development for each skilled man in companies employing more than 5,000 people worked out at $\$ 40,900$, or 9 per cent more than the average for American industry as a whole.

\section{Fusion at Culham}

The Culham Laboratory of the U.K. Atomic Energy Authority seems to be settling down to the long haul in the search for a power source using nuclear fusion. The contributions by members of the laboratory to the Royal Society symposium on the subject last week showed that new work continues to expose as many problems as it solves. The laboratory also seems unconcerned at the suggestion that support for the laboratory may be reduced-the subject of a recent letter to the London Times (Nature, 211, 899; 1966). The present annual budget of the Culham Laboratory is about $£ 4$ million, which represents perhaps 10 per cent of the total international expenditure in the field. It is meaningful to speak of an international effort, because this is a field in which collaboration between scientists is more than a pious hope; at Culham, for instance, up to a quarter of the staff at any time are foreign visitors, either on fixed term associateships paid by Culham, or as shorter term visitors, paid by their home laboratories.

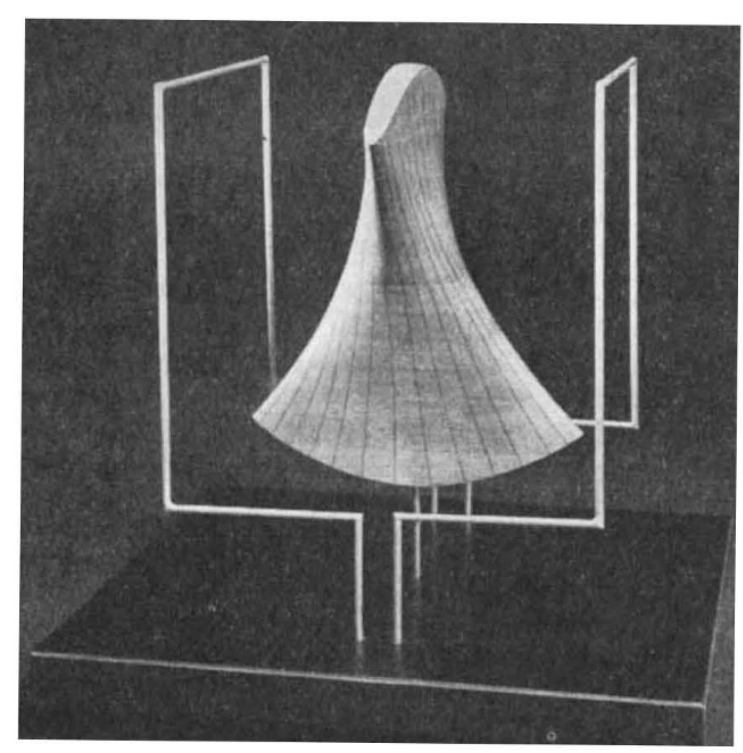

Fig. 1. Model of a magnetic well generated by a tube-edge conductor.
At least the principles on which a nuclear fusion reactor will be based seem to be established. A plasma - a mixture of bare nuclei and free electronsmust be established and maintained at very high temperature for long enough for the fusion reactions between the nuclei to produce a net gain of energy. Producing the plasma is easy compared with maintaining it; the most likely way of containing it is by magnetic fields, but plasmas have shown themselves adept at escaping from magnetic containers by a variety of instabilities. Fig. 1 shows one type of magnetic well which is being investigated at Culham, in which the magnetic field strength increases in all directions away from the centre. In the Phoenix experiment, plasma is fed slowly into the well particle by particle, and the density gradually built up to about $10^{9}$ particles $/ \mathrm{cm}^{3}$. One gross form of instability has been reduced by this technique, but it has revealed other forms of instability for which there seems to be no immediate solution. A working reactor would require densities greater by a factor of $10^{5}$, and much longer residence times in the well.

\section{Methane Cinderella}

THE change in the advertising symbol of the British gas industry from the comfortable Victorian "Mr. Therm" to the dynamic "High Speed Gas" seems to reflect changes in the attitude of gasmen themselves. They feel that the North Sea gas strike will give the industry a new lease of life and bolster up the British economy in the process. This was the optimistic tone of the Duke of Edinburgh's speech to the Institute of Gas Engineers on November 14, when he described the past 10 years as a "Cinderella story".

Despite this optimism, the benefits of cheap North Sea gas are by no means assured, and the Gas Council has a difficult path ahead. The most immediate hurdle to overcome is to settle a price. It is an open secret that the Council hopes to buy the gas for as little as 1 or 1.5 pence per therm while the oil companies think 4 pence or 4.5 pence more reasonable. The Gas Council is apparently thinking of a cost-plus price based on its own experience in the North Sea, but the oil companies hanker after the kind of price they might get in a free market. The strength of this difference of opinion is indicated by the protracted negotiations between the Shell-Esso group and the Gas Council. At least a part of the problem is that the Gas Council signed a 3 year agreement in April 1966 with British Petroleum to supply a minimum of $50 \times 10^{6}$ cubic feet of gas a day at 5 pence a therm; other oil companies do not see why second comers should be so ill favoured. They are not entirely mollified by the recollection that the British Petroleum price was fixed by the Minister of Power in the hope of encouraging exploration; he said at the time that it was not a precedent.

Another reason why the gas industry cannot look to the future with unbridled optimism is the nature of the gas fields themselves. The oil companies were lucky to strike gas fairly early in their exploration, but since then several dry holes have been drilled and it is possible that there is not much more gas to be discovered. The Gas Council wants the field to provide $4,000 \times 10^{6} \mathrm{ft}^{3}$ a day for 15 years, but nobody knows whether that will be easy. It also looks as if the structures in the rock under the North Sea are relatively tight, and that the gas may occur in a number of small 